\title{
Using Epidemiology and Genomics to Understand Osteosarcoma Etiology
}

\author{
Sharon A. Savage and Lisa Mirabello \\ Clinical Genetics Branch, Division of Cancer Epidemiology and Genetics, National Cancer Institute, National Institutes of Health, \\ 6120 Executive Boulevard, EPS/7018, Rockville, MD 20892, USA \\ Correspondence should be addressed to Sharon A. Savage, savagesh@mail.nih.gov
}

Received 14 September 2010; Revised 9 November 2010; Accepted 19 December 2010

Academic Editor: Stephen Lessnick

Copyright ( ${ }^{2} 2011$ S. A. Savage and L. Mirabello. This is an open access article distributed under the Creative Commons Attribution License, which permits unrestricted use, distribution, and reproduction in any medium, provided the original work is properly cited.

\begin{abstract}
Osteosarcoma is a primary bone malignancy that typically occurs during adolescence but also has a second incidence peak in the elderly. It occurs most commonly in the long bones, although there is variability in location between age groups. The etiology of osteosarcoma is not well understood; it occurs at increased rates in individuals with Paget disease of bone, after therapeutic radiation, and in certain cancer predisposition syndromes. It also occurs more commonly in taller individuals, but a strong environmental component to osteosarcoma risk has not been identified. Several studies suggest that osteosarcoma may be associated with single nucleotide polymorphisms in genes important in growth and tumor suppression but the studies are limited by sample size. Herein, we review the epidemiology of osteosarcoma as well as its known and suspected risk factors in an effort to gain insight into its etiology.
\end{abstract}

\section{Introduction}

Osteosarcoma, the most common primary bone malignancy, typically during the adolescent growth spurt but there is a second, smaller peak in the elderly [1]. There are a limited number of proven risk factors associated with osteosarcoma. It occurs more frequently after therapeutic radiation for a different cancer, in individuals with certain cancer predisposition syndromes, and in those with Paget disease of the bone. However, the majority of osteosarcoma cases occur in the absence of these risk factors. Numerous studies of growth and other genetic risk factors have been conducted but strong data on risk for apparently sporadic osteosarcoma are limited. The primary goal of this paper is to examine the recent studies seeking to understand osteosarcoma etiology through epidemiology and studies of germline genetics (Figure 1).

\section{Osteosarcoma Epidemiology}

2.1. Incidence. Osteosarcoma represents approximately 55\% of child and adolescent malignant bone tumors in the US [1].
It is rarely diagnosed before the age of five, but the incidence increases with age until around puberty [1,3-7]. This primary peak is followed by a decrease and plateau in incidence in individuals between 25 and 60 years of age (Figure 2). A second, smaller peak is observed during the seventh and eighth decades of life; this bimodal age incidence distribution of osteosarcoma is observed worldwide [8]. This is also noted in childhood and adolescent osteosarcoma where rates are relatively consistent around the world, ranging between 3 to 4.5 cases/million population/year $[6,8-13]$. The rates in older persons have been less studied; current estimates are 1 to 2 cases/million population/year for persons aged 25 to 59 years and 1.5 to 4.5 cases/million population/year for persons over the age of $60[1,8]$. Elderly individuals have a higher incidence of osteosarcoma related to Paget disease of the bone or as a consequence of treatment for a different cancer $[1,6,14-16]$. In the US and Europe, osteosarcoma incidence has somewhat increased over time in younger cases $[1,6,12]$ and decreased in elderly individuals in the US [1].

In the US, using population data from the Surveillance, Epidemiology, and End Results (SEER) program, osteosarcoma incidence has been shown to vary by race based 


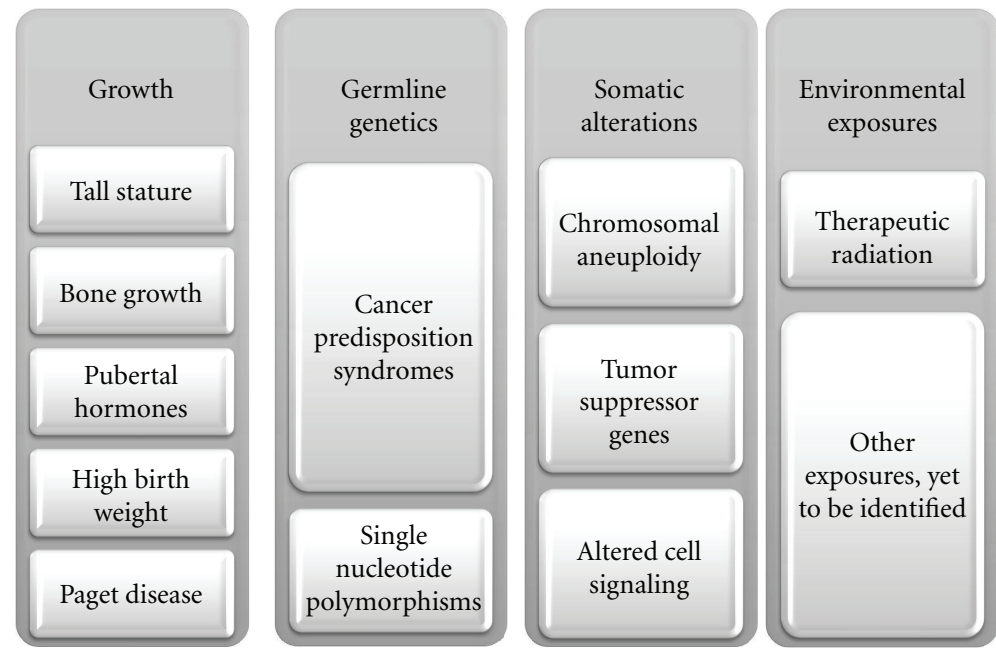

FIGURE 1: Potential contributing factors in the etiology of osteosarcoma.

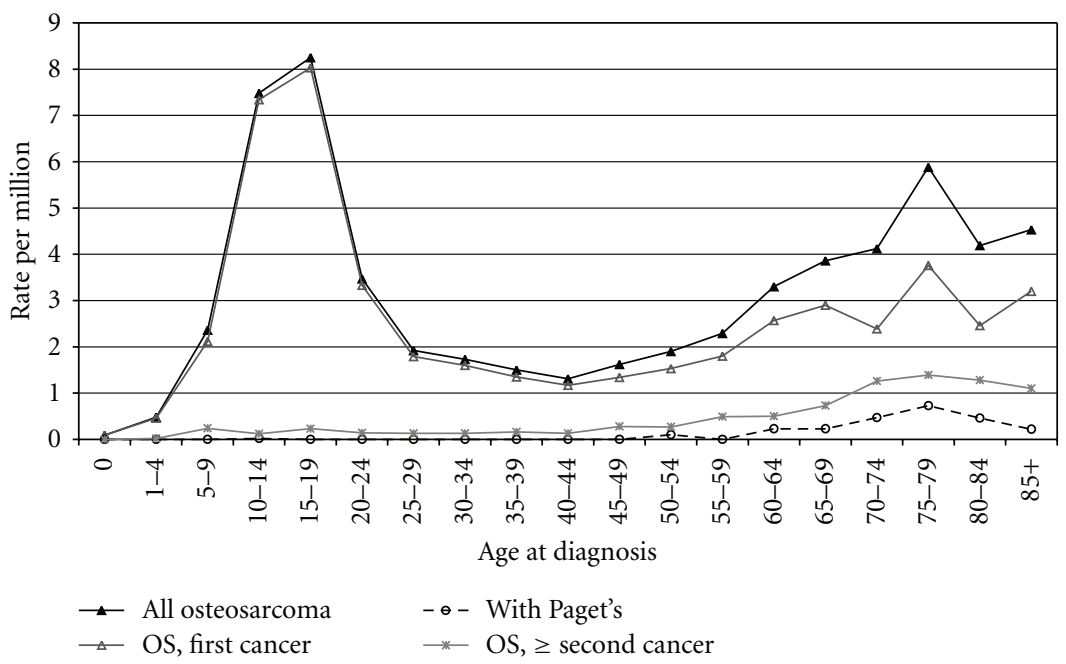

FIGURE 2: Incidence of osteosarcoma per million population. Data were derived from the Surveillance, Epidemiology, and End Results (SEER) program on the US population. Previously published by Mirabello et al. [2].

on the age of onset [17]: (1) in children and adolescents, the incidence is greatest in Asian/Pacific Islanders; (2) in individuals $25-59$ years of age, the incidence is greatest in Blacks; (3) in individuals over the age of 60, osteosarcoma incidence is greatest in Whites [1]. A higher incidence of childhood osteosarcoma has been reported in Italy [18], Latin America [8], and in two African countries, Sudan and Uganda [13] compared to other populations around the world. Lower rates have been reported in Western Australia compared to the US [19]. Higher rates of osteosarcoma in the elderly have been noted in the UK and Australia [8].

It has been reported that, when a wide range of ages are combined, males are affected with osteosarcoma more frequently than females $[1,3,4,6,8,12,19-21]$. However, it has also been reported that females less than 15 years of age have slightly higher rates than males in the same age group
$[1,5,6,14,22-26]$. In elderly patients, osteosarcoma is more common in Blacks [5] and in females, particularly those with a prior history of cancer [1]. In adolescence, incidence peaks at a later age and reaches higher rates in males (age $15-19$, peak rate of $9-15$ cases/million population) compared to females (age 10-14, peak rate of 6-10 cases/million population) $[1,6,8]$, which suggests that bone growth, hormonal changes, and/or development associated with puberty may be involved in osteosarcoma etiology. This relationship between osteosarcoma, hormones, and growth may also partly explain the slightly higher overall incidence in males compared to females.

2.2. Tumor Location. Osteosarcoma occurs most frequently in the lower long bones $[1,5,7,21]$ (Figure 3 ). In young patients, it most often arises at sites of rapid bone growth, 


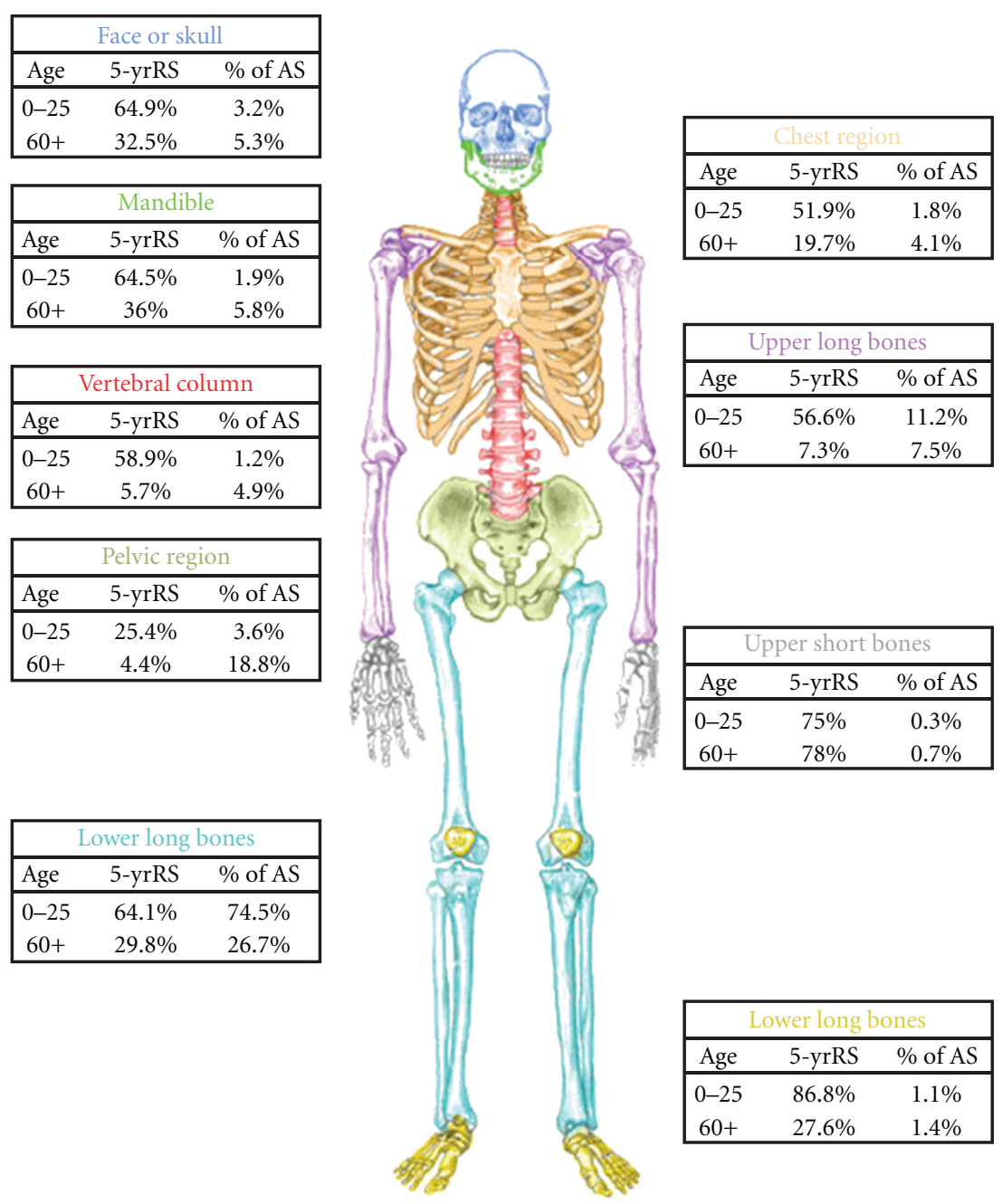

FIGURE 3: Five-year relative survival rates (RS) by anatomic site (AS) for individuals with osteosarcoma age 0-25 years and 60+ years in the US. The percent (\%) of AS is the \% of patients in that age group with osteosarcoma at that location. This figure was created using data from the SEER program in Mirabello et al. [2].

the metaphyses of long bones, such as the distal femur, proximal tibia, and proximal humerus $[1,21,27]$. The occurrence of osteosarcoma most frequently in the metaphyseal area adjacent to the growth plate of long bones [28], which are the sites of particularly rapid growth during the adolescent growth spurt, reinforces the relationship between bone growth and osteosarcoma formation. There may be an increased vulnerability at these physes due to the high cell turnover during puberty. The tendency of osteosarcoma to occur in the extremity bones decreases with age, although the most common site is still the lower long bones. The lower long bones account for approximately $80 \%$ of osteosarcoma in the young patients, $27-43 \%$ in middle aged and elderly persons $[1,3,16,29]$. In elderly patients, osteosarcomas often occur secondary to Paget's disease of the bone or some other benign bone lesion [14-16].

The anatomic site distributions do not vary significantly by sex or race in young patients [1] but there is more variability in middle-aged and elderly patients. This includes a higher frequency of osteosarcoma of the mandible in Blacks compared to Whites, and higher frequency of chest and upper long bone osteosarcoma but lower rates of vertebral, pelvic, or mandibular osteosarcoma in females compared to males [1].

2.3. Survival. Survival rates vary by age, gender, disease stage, and anatomic site (Figure 3). For children and adolescents, these rates are similar in most countries, ranging from 55$75 \%$; although, lower rates (19-39\%) have been observed in Slovakia, Estonia, and Denmark [1, 8, 30-33]. The fiveyear survival rate in persons aged $0-39$ years was $58 \%$ in northern England [12] and 53\% in Great Britain [26]. The 5year survival in Finland for the whole study population was $58 \%$ [34]. Survival at 5 years was $57 \%$ for patients of all ages, $68 \%$ for those $<41$ years, and $22 \%$ for patients older than 65 years at an institute in Italy $[35,36]$. Data for patients of all ages from the US National Cancer Database reported a 5year survival of 53.9\% [21], similar to the 54\% reported for all age cases at the M.D. Anderson Cancer Center [37]. SEER 
data in the US from 1973 to 2004 showed that the relative 5year survival rate for young-onset osteosarcoma was 61.6\%; it was $58.7 \%$ for middle aged persons and $24.2 \%$ for persons over 60 years of age [1]. This paper showed a sharp decrease in survival after age 50, with rates dropping from around $50 \%$ for patients in their 50 s to $17 \%$ for those in their midlate 60 s to only $11 \%$ for those in their 80 s. Others have also shown that survival rates in adults over age 40 years are lower than in younger patients with rates ranging from $18-55 \%$ [16, 21, 29, 36-39].

Females have higher survival rates than males $[1,12,21$, $26,32,33,40]$. Disease stage is an important prognostic factor in patients with osteosarcoma at all ages, with distant disease having a much lower 5-year survival rate than localized or regional disease $[1,32]$. Osteosarcoma survival rates are higher when it occurs in the short bones, and the poorest with osteosarcoma of the pelvic region and vertebral column for all ages $[1,3]$. Osteosarcoma pathology has also been suggested to affect survival, though this is difficult to evaluate in most reports because many of the subtypes consist of very small sample sizes and rates are thus unstable. However, parosteal osteosarcoma has been associated with a high survival rate [21], and osteosarcoma with Paget disease a low rate $[1,21]$. It has also been shown that patients with larger tumor size, metastatic disease, soft-tissue extension of the primary tumor, less tumor necrosis after neoadjuvant chemotherapy, inadequate surgical margins, or recurrence have significantly worse prognosis $[7,36-$ 38].

Older patients may have unique tumor biology, for example, more axial tumors or other factors associated with a poorer prognosis, such as Paget disease (see below) and response to therapy due to age-related adjustments in therapeutic regimens, which could contribute to their worse overall survival $[7,29,37]$. Overall, osteosarcoma survival has improved over time with each decade until the 1990s, but little thereafter $[1,6,26,31,32,34,40-43]$. It has likely improved with advancements in patient care and the advent of chemotherapy, but there is still a need for novel treatment and patient management strategies shown by the lack of improvement in the last decade.

\section{Environmental Exposures and Osteosarcoma}

Studies of environmental exposures and rare cancers, such as osteosarcoma, are challenging and often limited by sample sizes. Most studies are case-control, ecologic, and/or descriptive in nature. This is because the extremely large cohorts required to study these cancers are nearly impossible to conduct. For example, even in a cohort of one million individuals, only 4 or 5 would be expected to develop osteosarcoma. Studies of environmental exposures and osteosarcoma are often combined with studies of other bone tumors, including Ewing sarcoma and others. This makes separating the potentially etiologic clues even more challenging. The reader is referred to a recent, comprehensive review of these studies [44]. Two well-studied exposures are described below.
Many years ago, it was hypothesized that fluoride could contribute to osteosarcoma risk. This was based, in part, on the fact that it is taken up by and stored in bones and on in vitro data which suggested that fluoride could act as a mitogen on osteoblasts [45]. Studies of fluoride exposure and osteosarcoma risk have not yielded conclusive results and have generated significant controversy. The initial ecologic studies suggested that fluoride could contribute to bone cancer etiology, but subsequent studies did not confirm this finding (reviewed by Eyre et al., 2009 [44]). A more recent study did suggest an association between fluoride and osteosarcoma in males but not in females [46] but caution was suggested in its interpretation [47].

Therapeutic radiation is a proven risk factor for osteosarcoma. It was noted to occur more frequently than expected in survivors of Hodgkin disease who received therapeutic radiation $[48,49]$. Increased incidence of osteosarcoma was also noted in individuals who received Radium for ankylosing spondylitis (reviewed in [48]). However, very low doses of radiation received for medical evaluations, such as $\mathrm{X}$-rays or CT scans are not associated with osteosarcoma risk (reviewed in [50]).

\section{Growth and Osteosarcoma}

Since osteosarcoma occurs most commonly during puberty, a time of rapid bone growth and remodeling, it is highly plausible that factors related to growth and development play a role in osteosarcoma etiology. Case reports of osteosarcoma occurring in individuals with acromegaly, a growth disorder caused by over production of growth hormone, lent further support to this hypothesis [51]. Early studies suggested that individuals who were longer at birth and/or taller than their peers were at increased risk of osteosarcoma [52-55]. These associations are further supported by the strong positive association of sporadic osteosarcoma and height in canines [56].

Osteosarcoma incidence is highest during puberty when endogenous sex hormones, growth hormones, and insulinlike growth factor 1(IGF1) levels are at their highest, so this biological pathway is likely to play an important role in osteosarcoma etiology. Insulin-like growth factors (IGFs) play critical roles in carcinogenesis and circulating levels are associated with risk of several cancers [57], including prostate, breast, colorectal, and lung cancer [58]. IGF1 is a potent mitogen for human osteosarcoma cell lines $[59,60]$. The overexpression of insulin-like growth factor 2 (IGF2) and loss of IGF2 imprinting occurs in diverse cancers [61], further suggesting a role for this pathway in carcinogenesis. In addition, one small study identified single nucleotide polymorphisms (SNPs) in IGF2R as potential risk factors for osteosarcoma (see below) [62].

4.1. Height. The association between taller stature and increased risk of developing osteosarcoma was first reported in 1967 [63]. That study compared the height of 85 individuals with osteosarcoma to 202 controls between 1945 and 1965 and found that the cases were taller than controls. 
Two subsequent studies of 54 and 18 cases each which used percentiles of height also noted that the osteosarcoma cases were taller than expected [54, 64]. Five additional studies $[53,55,65-67]$ confirmed the association of increased height and osteosarcoma risk but eight others [52, 68-74] did not find an association between height and osteosarcoma risk. The discrepancies among these studies could be a result of limited sample sizes, variable methods and control selection procedures, and thus limited statistical power. However, the largest study, a cohort study of 962 patients with osteosarcoma which used standard deviation scores to evaluate the relative height of patients, found that patients with osteosarcoma were taller than average but the association was primarily in those less than 18 years of age [53].

A recent meta-analysis of height and osteosarcoma compiled individual osteosarcoma patient data on 1067 osteosarcoma cases derived from 5 published $[52,54,66,67$, 73 ] and 2 unpublished studies of height (Mirabello et al., Under Review). Cases were compared to age- and gendermatched 1000 simulated controls per case based on the 2000 US National Center for Health Statistics Growth Charts. That study showed that "taller-than-average" (51st-89th percentile) and "very tall" individuals ( $\geq 90$ th percentile) had an increased risk of osteosarcoma (odds ratio 1.40, 95\% CI 1.13-1.73, and odds ratio 2.63, 95\% CI 1.98-3.49, resp., $\left.P_{\text {trend }}<0.0001\right)$.

The meta-analysis (Mirabello et al., Under Review), and a separate study of 962 patients with osteosarcoma [53], which was not included in the meta-analysis, confirm that taller stature is associated with osteosarcoma. However, the specific basis for this association is not known. For example, there are currently no data in the literature on osteosarcoma and patient height that also consider parental height. The incidence of osteosarcoma does not vary widely around the world but the average adult height varies based on country of origin [75]. Individuals with a more rapid growth velocity during puberty could potentially have increased risk of osteosarcoma because cell division is occurring more rapidly. Attaining a greater height than expected based on parental heights could also be a risk factor because of the increased bone growth required. Future studies of parental height and growth velocity will be helpful in understanding these differences.

4.2. Birth Weight. Numerous epidemiologic studies have evaluated associations between high birth weight and cancer. This is based on the hypothesis that high birth weight may be the result of multiple factors that are also associated with cancer. For example, IGFs are important in fetal development [76] and are also associated with cancer risk [57]. Higher birth weight has been associated with several childhood cancers, including acute lymphoblastic leukemia (ALL) [77-79], primary brain tumors [80], rhabdomyosarcoma [81], and Wilms' tumor [82, 83]. Interestingly, recent studies of ALL and Wilms' tumor suggest that the strongest associations are in females with high birth weight $[82,84]$. There are also several studies suggesting associations between high birth weight and adult-onset cancers, including prostate and breast cancer $[85,86]$.
Review of the literature identified five published studies that evaluated the potential association between birth weight and osteosarcoma; four were null $[65,74,79,87]$, and one showed an association between higher birth weight and osteosarcoma [52]. The inconsistencies in the published data on birth weight may also be due to small sample sizes and/or inconsistent methods. A meta-analysis of the raw data from two published $[52,79]$ and one unpublished study of birth weight and osteosarcoma compared the birth weights of 434 individuals with osteosarcoma to age- and gender-matched controls (1000 simulated controls per case) derived from US growth charts (Mirabello et al., Under Review). In that study, individuals with high birth-weight $(\geq 4046 \mathrm{~g})$ had a marginally significant increased risk of osteosarcoma (OR 1.35, 95\% CI 1.01-1.79). Females with high birth-weight, but not males, had an increased risk of OS (OR 1.49, 95\% CI 1.00-2.22). Overall, the association between birth weight and osteosarcoma is not as strong as the height association, but it is similar in magnitude to other cancers. It remains conceivable that prenatal growth and factors that influence it, such as growth factors and hormones, contribute to osteosarcoma risk.

4.3. Paget Disease and Osteosarcoma. Paget disease of bone is a relatively common metabolic bone disorder that typically occurs in older individuals $[88,89]$. It is characterized by highly exaggerated bone remodeling caused by abnormalities in osteoclast regulation. Sarcomatous transformation is rare but associated with a high mortality rate. The incidence of osteosarcoma secondary to Paget disease is not precisely known, but studies estimate that about $1 \%$ of patients with Paget disease will develop osteosarcoma [90]. In elderly persons, about half of the osteosarcomas reported are estimated to be associated with Paget disease.

The co-occurrence of osteosarcoma in the setting of abnormal bone remodeling due to Paget disease of the bone suggests that osteosarcoma may be etiologically related to abnormal bone remodeling $[90,91]$. This could appear to be the case in elderly individuals but the role of abnormal bone remodeling in osteosarcoma adolescents is not known. It is conceivable that a subset of younger patients have increased genetic risk and that there could be overlap with genes that contribute to the etiology of Paget disease. Paget disease is genetically heterogeneous but recent studies implicate the RANK-NF- $\kappa$ B signaling pathway [89]. Mutations in SQSTM1, a downstream scaffold protein in this pathway, are associated with familial Paget disease [92]. Many, but not all, of the associated mutations occur in the ubiquitinassociated domain of the p62 protein which is encoded by the SQSTM1 gene [88]. Ubiquitin-associated proteins, such as $\mathrm{p} 62$, are important in the RANK-NF- $\kappa \mathrm{B}$ signaling pathway which promotes osteoclastogenesis and formation.

\section{Genetic Risk Factors}

Chromosomal aneuploidy is common in osteosarcoma cells which suggests that somatic or germline chromosomal instability could potentially predispose an individual to 
TABLE 1: Inherited disorders associated with increased rates of osteosarcoma.

\begin{tabular}{llll}
\hline Disorder & Gene & Chromosome & $\begin{array}{c}\text { Autosomal } \\
\text { inheritance pattern }\end{array}$ \\
\hline Li-Fraumeni Syndrome & TP53, tumor protein p53 & $17 \mathrm{p} 13.1$ & Dominant \\
\hline Retinoblastoma & RB1, retinoblastoma 1 & Dominant \\
\hline Rothmund Thomson Syndrome & $\begin{array}{l}\text { REQL4, RecQ protein-like 4, } \\
\text { DNA helicase }\end{array}$ & $8 \mathrm{q} 24.3$ & Recessive \\
\hline Werner Syndrome & $\begin{array}{l}\text { WRN, Werner syndrome, RecQ } \\
\text { helicase-like }\end{array}$ & $8 \mathrm{p} 12$ & Recessive \\
\hline Bloom Syndrome & $\begin{array}{l}\text { BLM, Bloom syndrome, RecQ } \\
\text { helicase-like }\end{array}$ & $15 \mathrm{q} 26.1$ & Recessive \\
\hline Diamond Blackfan Anemia & $\begin{array}{l}\text { Ribosomal protein genes, } \\
\text { including RPS19, RPL5, RPL11, } \\
\text { RPL35A, RPS24, RPS17, and } \\
R P S 7\end{array}$ & multiple & Dominant \\
\hline
\end{tabular}

osteosarcoma $[93,94]$. There are numerous studies of the somatic changes present in osteosarcoma cells but a common somatic defect has not yet been identified. Osteosarcoma is associated with several cancer predisposition syndromes that are caused by highly penetrant germline mutations as described in Table 1. These disorders are extremely rare and not a common cause of osteosarcoma. However, they may provide important insights into osteosarcoma etiology because the same genes that are associated with these disorders are often also disrupted in osteosarcoma tissues. Common germline genetic variants, such as SNPs, are associated with risk of numerous diseases, including cancer. The role that they play in sporadic osteosarcoma is not known, but several pilot studies have sought to understand this (Table 2).

5.1. Inherited, Cancer-Prone Disorders. Inherited cancer predisposition syndromes are a heterogeneous group of disorders. There are several disorders in which higher rates of osteosarcoma are noted (Table 1). Studies of these disorders have provided important clues to understanding osteosarcoma etiology.

The careful characterization of families with high rates of breast cancer, sarcomas, and other cancers by $\mathrm{Li}$ and Fraumeni Jr. in 1969 led to the recognition of the syndrome now known as Li-Fraumeni syndrome (LFS) [101, 102]. The classic LFS is clinically diagnosed based on family history which includes a personal history of a sarcoma diagnosed under the age of 45 , a first-degree relative with cancer under age 45, and another first- or second-degree relative with cancer diagnosed under age 45 or sarcoma at any age. LFS is caused by autosomal dominant germline mutations in TP53 [102, 103] although approximately 30\% of individuals who meet clinical criteria for LFS do not have a TP53 mutation. Additional clinical descriptions and criteria for mutation testing in individuals with suspected LFS are reviewed in [102]. The p53 protein, encoded by TP53, is crucial for normal cell growth, apoptosis, DNA repair, and numerous other cellular processes. The p53 gene is mutated in a majority of somatic tumor tissues, many of which disrupt the DNA-binding domain and result in a loss of tumor suppressor function [104]. Many, but not all, osteosarcomas have TP53 mutations but these have not consistently been correlated with disease stage or prognosis [105].

Retinoblastoma is a malignant retinal tumor that typically occurs prior to the age of 5 . It is caused by mutations in the RB1 tumor suppressor gene [106]. The RB1 gene encodes the $\mathrm{Rb}$ protein which is critical in normal cell cycle and differentiation processes. Loss of normal $\mathrm{Rb}$ function is noted in several sporadic human tumors, including apparently sporadic osteosarcoma. In addition, osteosarcoma is the most common second tumor in patients with retinoblastoma. It occurs more frequently than expected in individuals with $R B 1$ mutations whether or not they had radiation therapy $[107,108]$. The standardized incidence ratio (SIR) for osteosarcoma occurring after retinoblastoma was 406-fold over expected for individuals who had radiation and 69-fold over expected for those who had not received radiation therapy. This suggests that both primary genetic and gene/environment interactions contribute to osteosarcoma development in the setting of a germline $R B 1$ mutation, and this may also be the case in apparently sporadic osteosarcoma.

Increased rates of osteosarcoma are also present in individuals with germline mutations in DNA helicase genes, including Rothmund Thomas syndrome (RTS), Werner syndrome, and Bloom syndrome. RTS is a rare, autosomal recessive disorder caused by mutations in the DNA helicase RECQL4 (reviewed in $[109,110]$ ). It has a characteristic sun-sensitive rash which presents in infancy and then enters a chronic phase with poikiloderma through adulthood. Individuals with RTS may also have small stature, skeletal dysplasias, sparse hair, or cataracts. Osteosarcoma is the most common cancer in RTS; one study of 41 patients found that $32 \%$ had osteosarcoma [111]. The role of RECQL4 in sporadic osteosarcoma is not well understood. Since the DNA helicases are critical for normal DNA structure and function, it is feasible that proteins in this family are likely to be important in carcinogenic processes and could contribute to the DNA damage and chromosomal aberrations seen in osteosarcoma cells. 
TABLE 2: Association studies of single nucleotide polymorphisms and osteosarcoma risk. Abbreviations: SNP: single nucleotide polymorphism; OR: odds ratio; CI: confidence interval.

\begin{tabular}{|c|c|c|c|c|}
\hline $\begin{array}{l}\text { First Author, Year, } \\
\text { Reference }\end{array}$ & $\begin{array}{l}\text { No. } \\
\text { cases/no. } \\
\text { controls }\end{array}$ & Study Design & Gene & Main Finding(s) \\
\hline $\begin{array}{l}\text { Patiño-Garcia, 2000, } \\
\text { [95] }\end{array}$ & $63 / 111$ & Case-Control & $\begin{array}{l}\text { Tumor Necrosis Factor- } \alpha \\
(T N F)\end{array}$ & $\begin{array}{l}\text { Evaluated } 3 \text { SNPs in the promoter. TNF- } \alpha-238 \mathrm{G}>\mathrm{A} \\
\text { was inversely associated with risk (OR } 0.17,95 \% \mathrm{CI} \\
0.04-0.76, P=0.0095 \text { ) }\end{array}$ \\
\hline \multirow{3}{*}{ Ruza, 2003, [66] } & \multirow{3}{*}{$72 / 143$} & \multirow{3}{*}{ Case-Control } & Vitamin D Receptor (VDR) & $\begin{array}{l}3 \text { SNPs (FokI, ApaI, TaqI) studied. FokI Ff genotype } \\
\text { associated with increased risk (OR 1.78, 95\% CI 1.0- } \\
3.16, P=0.048)\end{array}$ \\
\hline & & & Estrogen Receptor (ESR1) & $\begin{array}{l}2 \text { variants (Pvu II and } \mathrm{XbaI} \text { ) evaluated were not } \\
\text { associated with osteosarcoma }\end{array}$ \\
\hline & & & Collagen $1 \alpha 1$ (COL1A1) & $\begin{array}{l}1 \text { variant studied (Msc 1) was not associated with } \\
\text { osteosarcoma. }\end{array}$ \\
\hline Savage, 2007, [96] & $104 / 74$ & $\begin{array}{l}\text { Hospital-based } \\
\text { Case-Control }\end{array}$ & Tumor Protein p53 (TP53) & $\begin{array}{l}12 \text { tag-SNPs in TP53 genotyped. Recessive model } \\
\text { noted potential increased risk with rs } 1642785 \\
(\mathrm{IVS}+38 \mathrm{C}>\mathrm{G} \text {; OR } 6.7,95 \% \text { CI 1.06-41.6, } P=0.04) \\
\text { and rs } 1042522(\mathrm{Ex} 4+119 \mathrm{C}>\mathrm{G}, \mathrm{P} 72 \mathrm{R} ; \mathrm{OR} 7.5,95 \% \mathrm{CI} \\
1.2-46.3, P=0.03) .\end{array}$ \\
\hline Savage, 2007, [62] & $104 / 74$ & $\begin{array}{l}\text { Hospital-based } \\
\text { Case-Control }\end{array}$ & $\begin{array}{l}\text { Insulin-like Growth Factor } \\
2 \text { Receptor }(I G F 2 R)\end{array}$ & $\begin{array}{l}\text { Evaluated } 52 \text { SNPs in } 13 \text { growth-related genes. Two } \\
\text { linked IGF2R SNPs, rs998075 (Ex16+88G }>\text { A) and } \\
\text { rs } 998074 \text { (IVS16+15C }>\text { T), associated with increased } \\
\text { risk (haplotype OR 2.04, 95\% CI 1.29-3.24, } P= \\
0.006 \text { ). }\end{array}$ \\
\hline Koshkina, 2007, [97] & $123 / 510$ & Case-Control & $\begin{array}{l}\text { Fas (TNF receptor } \\
\text { superfamily, member 6; } \\
F A S \text { ) }\end{array}$ & $\begin{array}{l}4 \text { SNPs in Fas studied. Increased risk with exon } \\
3,18272 \mathrm{~A}>\mathrm{G} \text {, most pronounced in non-Hispanic } \\
\text { whites (OR } 2.3,95 \% \mathrm{CI} 1.2-4.6, P=0.014 \text { ) }\end{array}$ \\
\hline \multirow[t]{2}{*}{ Toffoli, 2009, [98] } & \multirow[t]{2}{*}{$201 / 250$} & \multirow[t]{2}{*}{ Case-Control } & $\begin{array}{l}\text { Mdm2 p53 binding protein } \\
\text { homolog (MDM2) }\end{array}$ & $\begin{array}{l}1 \mathrm{SNP} \text { in } M D M 2 \text { studied, rs } 2279744(\mathrm{SNP} 309 \mathrm{~T}>\mathrm{G}) \text {, } \\
\text { was associated with high-grade osteosarcoma in } \\
\text { females }\end{array}$ \\
\hline & & & Tumor Protein p53 (TP53) & $\begin{array}{l}1 \text { SNP evaluated, rs1042522 (Ex4+119C }>\text { G, P72R), } \\
\text { was associated with survival. }\end{array}$ \\
\hline $\mathrm{Hu}, 2010,[99]$ & $168 / 168$ & Case-Control & $\begin{array}{l}\text { Transforming growth factor } \\
\text { beta receptor } 1 \text { (TGFBR1) }\end{array}$ & $\begin{array}{l}\left.1 \text { variant evaluated (TGFBR }{ }^{*} 6 \mathrm{~A}\right) \text { was associated } \\
\text { with increased susceptibility (OR 4.6, } 95 \% \text { CI } 2.3- \\
7.9, P=0.002 \text { ) }\end{array}$ \\
\hline $\begin{array}{l}\text { Mirabello, 2010, } \\
{[100]}\end{array}$ & $99 / 1430$ & $\begin{array}{l}\text { Hospital-based } \\
\text { Case-Control }\end{array}$ & $8 \mathrm{q} 24$ region & $\begin{array}{l}\text { Evaluated } 214 \text { SNPs, including } 9 \text { previously asso- } \\
\text { ciated with cancer. Strongest association noted at } \\
\text { rs } 896324 \text { in additive model (OR } 1.75,95 \% \text { CI } 1.13- \\
2.69, P=0.01 \text { ) }\end{array}$ \\
\hline
\end{tabular}

Bloom syndrome, caused by autosomal recessive inheritance of mutations in the BLM helicase, also has a characteristic rash, but not true poikiloderma [112]. Individuals have severe pre- and postnatal growth retardation, learning disabilities, and high rates of cancers. The most common cancers are epithelial, hematopoietic, lymphoid, connective tissue, germ cell, nervous system, and kidney cancers. Three out of 168 individuals with Bloom syndrome listed in the Bloom syndrome registry were reported to have a sarcoma between 1954 and 2000 [112]. While osteosarcoma is still rare in Bloom syndrome, it is more common in this disorder than in the general population. The role of $B L M$ mutations in osteosarcoma somatic cells is not well described.

Werner syndrome is a premature aging syndrome which typically presents after the first decade of life $[113,114]$. It is caused by mutations in the WRN DNA helicase and inherited in an autosomal recessive manner. Individuals with Werner syndrome typically have characteristic "bird" facies, short stature, parental consanguinity, cataracts, atrophic skin, and signs of premature aging such as atherosclerosis. They are at increased risk of osteosarcoma as well as other malignancies $[115,116]$.

Diamond Blackfan anemia (DBA) is another inherited disorder associated with increased risk of osteosarcoma [117]. DBA is an inherited red blood cell aplasia with a broad phenotypic spectrum. Patients have variable degrees of anemia, normal leukocytes and platelets, occasional physical malformations, and increased risk of acute myelogenous leukemia, myelodysplastic syndrome, and solid tumors. Approximately $40 \%$ of patients have an identifiable mutation in a gene important in ribosomal function (RPS19, RPL5, RPL11, RPL35A, RPS24, RPS17, or RPS7). Osteosarcoma was noted in three of the 354 patients in the DBA registry in 2001 [118]. The role of these ribosomal proteins in 
osteosarcoma biology is unexplored. However, the higher than expected occurrence of osteosarcoma in patients with DBA is notable and warrants further study of ribosomal function in osteosarcoma.

5.2. Inherited, Cancer-Prone Disorders. The inherited disorders caused by rare, highly-penetrant mutations and associated with osteosarcoma described above explain only a very small percentage of all osteosarcoma cases. It occurs more often in individuals without a family history of cancer or other medical problems. Several studies have been conducted in an effort to understand the contribution of common genetic variants, such as SNPs, to osteosarcoma risk (Table 2) although the vast majority await replication. SNPs are the most common form of genetic variation in the genome; approximately 10 million with minor allele frequencies of at least $1 \%$ are thought to be present in the genome. Most SNPs do not alter gene expression or protein function, but a subset can have subtle, yet important, biological effects. For example, an SNP in the promoter of the MDM2 gene increases the affinity of the Spltranscription factor which results in higher MDM2 levels and p53 pathway attenuation [119].

Most of the studies of SNPs and osteosarcoma conducted to date have been limited by sample size and therefore should be considered exploratory in nature (Table 2). These studies were based on a priori hypotheses that the genes of interest were potentially important in osteosarcoma biology. The first such study evaluated three SNPs in the promoter of the Tumor Necrosis Factor- $\alpha$ (TNF) gene in 63 osteosarcoma cases and 111 controls from Spain [120]. The TNF protein is a proinflammatory cytokine that has important roles in cellular proliferation and differentiation. It is also involved in bone remodeling and is a component of the RNKL pathway described above. SNPs in the TNF promoter have also been noted to affect protein expression. That study suggested that the TNF-238G>A was inversely associated with osteosarcoma. The TNF-308G $>$ A variant was not associated with osteosarcoma. The authors also evaluated these genotypes in 47 individuals with Ewing sarcoma but did not find an association.

In a second study, the same group hypothesized that variants in the estrogen receptor (ESR1), vitamin D receptor $(V D R)$, and/or collagen $1 \alpha 1$ (COL1A1) gene could be osteosarcoma risk factors. Variants in ESR1 could be important in osteosarcoma since estrogen is critical during puberty which is the key time of risk for osteosarcoma. The VDR and COL1A1 genes are required for proper bone formation and thus, if aberrations are present, could be associated with osteosarcoma. A total of 72 osteosarcoma cases and 143 controls were evaluated. Ruza et al. found that the $\mathrm{F} f$ genotype of $V D R$ was associated with increased risk of osteosarcoma (odds ratio [OR] 1.78, 95\% confidence interval [CI] 1.0-3.16, $P=0.048$ ) [66]. Variants in ESR1 or COL1A1 were not associated with osteosarcoma.

Since mutations in TP53 cause LFS and osteosarcoma is a defining tumor of the syndrome, SNPs in TP53 were evaluated as potential osteosarcoma risk factors in the Bone
Disease and Injury Study of Osteosarcoma (BDISO), a hospital-based study of 104 cases and 74 controls [96]. Subjects genotyped were whites from the US Twelve tag-SNPs were genotyped and several inheritance models evaluated. The recessive inheritance model suggested that rs1642785 $($ IVS $+38 \mathrm{C}>\mathrm{G}$ ) and rs1042522 (Ex4+119C $>\mathrm{G}$, Pro72Arg) were associated with osteosarcoma risk. However, these genotypes were quite rare and this study, like those described above, was limited by its small sample size.

In a different study of the p53 pathway, Toffoli et al. genotyped the Pro72Arg (rs1042522, Ex4+119C>G) SNP in TP53 and the MDM2 -309 promoter SNP (rs2279744, T>G) in 201 osteosarcoma cases and 250 controls from Italy [98]. The Pro72Arg SNP in TP53 has been associated with risk of several cancers, including lung and breast cancer (reviewed in [121]). In addition, the presence of the 72Arg allele was correlated with earlier age of cancer onset in individuals with LFS [122]. The MDM2 protein is an important regulator of TP53 function, and the $-309 \mathrm{~T}>\mathrm{G}$ SNP is associated with altered MDM2 expression. LFS patients with the G allele have an earlier age of onset of cancer [122]. In addition, this MDM2 SNP is also associated with risk of several cancers [121]. This osteosarcoma study noted that the MDM2309 SNP was only associated with high-grade osteosarcoma in females. The TP53 Pro72Arg SNP was not associated with osteosarcoma risk but an association with survival was suggested. This study did not report results of a recessive genetic model so direct comparison with the BDISO TP53 findings in osteosarcoma was not possible.

The first study to evaluate SNPs in growth-related genes did so based on the hypothesis that since osteosarcoma most commonly occurs during a period of active growth, that variants in genes that regulate pubertal growth could be important osteosarcoma risk factors. Common SNPs in 13 growth-related genes were also evaluated as candidate risk modifiers in the BDISO. Of the 52 SNPs evaluated, two correlated SNPs in insulin-like growth factor receptor 2 (IGF2R, rs998075 and rs998074) were associated with increased risk of osteosarcoma (OR 2.04, 95\% CI 1.29-3.24) [62]. One of those SNPs, rs 998075 (Ex16+88G $>A)$, resulted in loss of methylation in a CpG island but the impact of this alteration on IGF2R protein function is not known. As noted above, the IGFs are potential regulators of carcinogenesis in several cancer types and IGF1 levels have been associated with cancer risk. Followup of these findings in osteosarcoma is needed to better understand how genetic variation in IGF2R contributes to its etiology.

SNPs in the 8q24 chromosomal region are being intensely studied because genome-wide association studies (GWAS) have consistently found them to be associated with risk of adult onset cancers, including prostate, breast, colon, and others [123-125]. Therefore, we recently evaluated 214 SNPs in $8 \mathrm{q} 24$ with a focus on the 9 SNPs which were previously associated with cancer in GWAS [100]. Ninety-nine cases and 65 controls plus an additional 1365 controls from the Prostate, Lung, Colorectal, Ovarian (PLCO) cancer screening trial were genotyped. All subjects were self-identified whites. Associations with the 9 SNPs previously associated with cancer were not noted in this study. Overall, seven SNPs 
were associated with osteosarcoma; the strongest result was noted for SNP, rs896324 (OR 1.75, 95\% CI 1.13-2.69). These SNPs are in slightly different locations than the SNPs associated with other cancers. The details of $8 \mathrm{q} 24$ are still being explored, but a long-range regulator of the MYC proto-oncogene may be present in this region [126]. MYC inhibition was suggested to cause differentiation of osteosarcoma cells into mature osteocytes in a mouse model [127]. The combination of these findings suggests that further study of the 8q24 locus may yield important insights into the regulation of $\mathrm{MYC}$ and its role in osteosarcoma pathogenesis.

The Fas protein (gene name FAS, or TNFRSF6) is a member of the TNF receptor superfamily and plays a central role in programmed cell death. Genetic variants in FAS have been associated with increased risk of several cancers, such as melanoma, gastric, and renal cell cancer [128, 129]. Based on this, Koshkina et al. hypothesized that SNPs in FAS may be osteosarcoma risk factors. They evaluated four SNPs in FAS in 123 osteosarcoma cases and 510 controls from the US [97]. An important limitation of this study is the fact that the study subjects were of variable ethnicity; $51.2 \%$ of cases (63) and $78 \%$ of controls (398) were described as non-Hispanic whites. An SNP in exon 3 (18272A $>$ G, dbSNP number not given) was associated with increased risk of osteosarcoma in non-Hispanic whites (OR 2.3, 95\% CI 1.2-4.6).

TGF- $\beta$ signaling is important in the regulation of cellular proliferation. A functional polymorphisms, referred to as TGFBR $1 * 6 \mathrm{~A}$, is caused by the deletion of 3 GCG triplets which code for alanine in exon 1 . It is a hypomorphic variant that results in reduced TGF- $\beta$ growth inhibitory signaling. The TGFBR $1 * 6$ A variant has been associated with breast and ovarian cancer, but not consistently associated with other cancer types [130]. Thus, the potential role of this variant was explored in a study of 168 osteosarcoma patients and 168 controls [99]. The authors found that both homozygosity and heterozygosity for the TGFBR $1 * 6 \mathrm{~A}$ variant resulted in increased risk of osteosarcoma in the Chinese population, in a gene-dose response pattern (OR 4.6, 95\% CI 2.2-7.97 and OR 2.9, 95\% CI 1.59-5.34, resp.).

As a whole, the studies conducted, to date, of common genetic variants and osteosarcoma risk have yielded promising results. Their strength lies in the fact that they have evaluated genes which have a high biologic likelihood of being related to osteosarcoma etiology based on laboratory and/or other epidemiologic studies. However, the results of all the studies described above and in Table 2 should be interpreted with caution because they all have small sample sizes and limited statistical power. Future, large, multiinstitutional, collaborative studies are required to obtain the necessary sample size and adequate statistical power to follow up these findings.

\section{Summary and Future Directions}

Some progress has been made in understanding the cause of osteosarcoma, but we still have much to learn. The biggest clue generated in the study of osteosarcoma epidemiology is its association with either rapid or abnormal growth. Its occurrence primarily during the adolescent growth spurt and association with tall height at diagnosis show that bone growth is clearly an important factor. It is not known whether or not tall stature, in and of itself, is the key, or if it is taller stature than expected based on parental heights or due to height velocity during puberty. An ongoing Children's Oncology Group epidemiology study which will investigate parental height and growth charts of children and adolescents with osteosarcoma will help shed light on this question. Future clinical and laboratory studies should also carefully evaluate the complex hormonal changes that occur before, during, and after puberty.

The association of osteosarcoma with the abnormal bone remodeling present in Paget disease also warrants more careful examination. The role of variants in genes of the RANKL-NF- $\kappa$ B signaling pathway, which are strongly associated with Paget disease, have not been thoroughly studied as potential osteosarcoma risk factors. The case reports of the occurrence of osteosarcoma in the setting of acromegaly, a state of abnormal growth hormone production, also warrant followup. Is the literature biased by these case reports, or is there an increased risk of osteosarcoma amongst individuals with acromegaly?

The studies of rare, but highly penetrant, cancer predisposition syndromes can shed some light on the biological mechanisms of osteosarcoma. In general, the cancers that occur in individuals with the cancer predisposition syndromes described above occur at much younger ages than in the same cancer types in the general population. The fact that several of these syndromes include osteosarcoma in the phenotype suggests that there may be common genetic mechanisms which also contribute to the apparently sporadic occurrence of osteosarcoma. It is also likely that the genetic contribution to cancers which occur in the first two decades of life, such as osteosarcoma, is greater than in cancers which do not occur until many decades later. In childhood cancer, there has been considerably less time for exposure to known and unknown environmental carcinogens.

The contribution of environmental exposures to osteosarcoma and to other cancers of children and young adults is not known. The heterogeneity and relative rarity of these cancers create significant complexity in study design and interpretation. In addition, it is likely that a combination of environmental exposure and genetic risk factors contribute to cancer risk. Large, longitudinal, cohort studies of the cancers of children and young adults are required to address these study design issues and likely contribution of multiple factors. The International Childhood Cancer Cohort Consortium (I4C) is a multiinstitutional, international collaborative group of childhood cohort studies that is working to better understand the etiology of childhood cancer [131]. However, even this large-scale effort will not be able to address osteosarcoma risk factors in detail, because of its rarity.

Like many cancers, the etiology of most osteosarcoma remains unknown. Epidemiology studies have provided many important clues, such as associations with puberty, 
height, and disorders of bone growth and remodeling. The genetic clues derived from the occurrence of osteosarcoma in the setting of germline mutations in genes such as TP53 and $R B 1$ suggest that the genetic contribution to what appears to be sporadic osteosarcoma may also be important. Understanding potential environmental contributions to osteosarcoma risk is very challenging because of its rarity and the fact that a single environmental exposure is not likely to be the primary cause. Numerous studies are underway which seek to improve our understanding of osteosarcoma etiology and through this understanding we will be better equipped to counsel patients and refine treatment strategies.

\section{References}

[1] L. Mirabello, R. J. Troisi, and S. A. Savage, "Osteosarcoma incidence and survival rates from 1973 to 2004: data from the surveillance, epidemiology, and end results program," Cancer, vol. 115, no. 7, pp. 1531-1543, 2009.

[2] L. Mirabello, R. J. Troisi, and S. A. Savage, "Osteosarcoma incidence and survival rates from 1973 to 2004: data from the Surveillance, Epidemiology, and End Results Program," Cancer, vol. 115, no. 7, pp. 1531-1543, 2009.

[3] H. D. Dorfman and B. Czerniak, "Bone cancers," Cancer, vol. 75, no. 1, pp. 203-210, 1995.

[4] K. K. Unni, Dahlin's Bone Tumors: General Aspects and Data on 11,087 Cases, Lippincott-Raven, Philadelphia, Pa, USA, 1996.

[5] A. P. Polednak, "Primary bone cancer incidence in black and white residents of New York State," Cancer, vol. 55, no. 12, pp. 2883-2888, 1985.

[6] C. A. Stiller, S. S. Bielack, G. Jundt, and E. Steliarova-Foucher, "Bone tumours in European children and adolescents, 1978-1997. Report from the Automated Childhood Cancer Information System project," European Journal of Cancer, vol. 42, no. 13, pp. 2124-2135, 2006.

[7] S. S. Bielack, B. Kempf-Bielack, G. Delling et al., "Prognostic factors in high-grade osteosarcoma of the extremities or trunk: an analysis of 1,702 patients treated on neoadjuvant cooperative osteosarcoma study group protocols," Journal of Clinical Oncology, vol. 20, no. 3, pp. 776-790, 2002.

[8] L. Mirabello, R. J. Troisi, and S. A. Savage, "International osteosarcoma incidence patterns in children and adolescents, middle ages and elderly persons," International Journal of Cancer, vol. 125, no. 1, pp. 229-234, 2009.

[9] D. M. Parkin, C. A. Stiller, and J. Nectoux, "International variations in the incidence of childhood bone tumours," International Journal of Cancer, vol. 53, no. 3, pp. 371-376, 1993.

[10] E. Steliarova-Foucher, C. Stiller, P. Kaatsch et al., "Geographical patterns and time trends of cancer incidence and survival among children and adolescents in Europe since the 1970s (the ACCIS project): an epidemiological study," Lancet, vol. 364, no. 9451, pp. 2097-2105, 2004.

[11] C. A. Stiller and D. M. Parkin, "Geographic and ethnic variations in the incidence of childhood cancer," British Medical Bulletin, vol. 52, no. 4, pp. 682-703, 1996.

[12] R. Eyre, R. G. Feltbower, P. W. James et al., "The epidemiology of bone cancer in 0-39 year olds in northern England, 1981-2002," BMC Cancer, vol. 10, article 357, 2010.
[13] D. M. Parkin, C. A. Stiller, G. J. Draper, and C. A. Bieber, "The international incidence of childhood cancer," International Journal of Cancer, vol. 42, no. 4, pp. 511-520, 1988.

[14] C. H. Price, "Osteogenic sarcoma; an analysis of the age and sex incidence," British Journal of Cancer, vol. 9, pp. 558-574, 1955.

[15] A. O. Sabanas, D. C. Dahlin, D. S. Childs Jr., and J. C. Ivins, "Postradiation sarcoma of bone," Cancer, vol. 9, pp. 528-542, 1956.

[16] A. G. Huvos, "Osteogenic sarcoma of bones and soft tissues in older persons. A clinicopathologic analysis of 117 patients older than 60 years," Cancer, vol. 57, no. 7, pp. 1442-1449, 1986.

[17] A. M. Linabery and J. A. Ross, "Trends in childhood cancer incidence in the U.S. (1992-2004)," Cancer, vol. 112, no. 2, pp. 416-432, 2008.

[18] D. M. Parkin, E. Kramarova, G. J. Draper et al., International Incidence of Childhood Cancer, IARC Scientific Publication, Lyon, France, 1998.

[19] J. B. Blackwell, T. J. Threlfall, and K. A. McCaul, "Primary malignant bone tumours in Western Australia, 1972-1996," Pathology, vol. 37, no. 4, pp. 278-283, 2005.

[20] J. G. Gurney, A. R. Swensen, and M. Bulterys, "Malignant bone tumors," in Cancer Incidence and Survival Among Children and Adolescents: United States SEER Program 19751995, L. A. G. Ries, M. A. Smith, and J. G. Gurney, Eds., pp. 99-110, National Cancer Institute, SEER Program, 1999.

[21] T. A. Damron, W. G. Ward, and A. Stewart, "Osteosarcoma, chondrosarcoma, and Ewing's sarcoma: national cancer data base report," Clinical Orthopaedics and Related Research, no. 459, pp. 40-47, 2007.

[22] M.R. Hanson, "Epidemiology of cancer in the young," in Cancer in the Young, A. Levine, Ed., Masson Publishing, New York, NY, USA, 1982.

[23] A. G. Glass and J. F. Fraumeni Jr., "Epidemiology of bone cancer in children," Journal of the National Cancer Institute, vol. 44, no. 1, pp. 187-199, 1970.

[24] S. E. Larsson and R. Lorentzon, "The incidence of malignant primary bone tumors in relation to age, sex and site. A study of osteogenic sarcoma, chondrosarcoma and Ewing's sarcoma diagnosed in Sweden from 1958 to 1968," Journal of Bone and Joint Surgery. Series B, vol. 56, no. 3, pp. 534-540, 1974.

[25] J. G. Gurney, R. K. Severson, S. Davis, and L. L. Robison, "Incidence of cancer in children in the United States: sex, race-, and 1- year age-specific rates by histologic type," Cancer, vol. 75, no. 8, pp. 2186-2195, 1995.

[26] C. A. Stiller, S. J. Passmore, M. E. Kroll, P. A. Brownbill, J. C. Wallis, and A. W. Craft, "Patterns of care and survival for patients aged under 40 years with bone sarcoma in Britain, 1980-1994," British Journal of Cancer, vol. 94, no. 1, pp. 2229, 2006.

[27] E. Kramárová and C. A. Stiller, "The International Classification of Childhood Cancer," International Journal of Cancer, vol. 68, no. 6, pp. 759-765, 1996.

[28] J. C. M. Clark, C. R. Dass, and P. F. M. Choong, "A review of clinical and molecular prognostic factors in osteosarcoma," Journal of Cancer Research and Clinical Oncology, vol. 134, no. 3, pp. 281-297, 2008.

[29] R. J. Grimer, S. R. Cannon, A. M. Taminiau et al., "Osteosarcoma over the age of forty," European Journal of Cancer, vol. 39, no. 2, pp. 157-163, 2003.

[30] Automatic Childhood Cancer Information System, Cancer Incidence and Survival by Registry and Tumour, IARC, 2003. 
[31] L. Foster, G. F. Dall, R. Reid, W. H. Wallace, and D. E. Porter, "Twentieth-century survival from osteosarcoma in childhood: trends from 1933 to 2004," Journal of Bone and Joint Surgery. Series B, vol. 89, no. 9, pp. 1234-1238, 2007.

[32] W. Ajiki, A. Hanai, H. Tsukuma, T. Hiyama, and I. Fujimoto, "Survival rates of childhood cancer patients in Osaka, Japan, 1975-1984," Japanese Journal of Cancer Research, vol. 86, no. 1, pp. 13-20, 1995.

[33] G. Gatta, R. Capocaccia, M. P. Coleman, L. A. Gloeckler Ries, and F. Berrino, "Childhood cancer survival in Europe and the United States," Cancer, vol. 95, no. 8, pp. 1767-1772, 2002.

[34] M. M. Sampo, M. Tarkkanen, A. H. Kivioja, M. H. Taskinen, R. Sankila, and T. O. Böhling, "Osteosarcoma in Finland from 1971 through 1990: a nationwide study of epidemiology and outcome," Acta Orthopaedica, vol. 79, no. 6, pp. 861-866, 2008.

[35] P. Picci, M. Mercuri, S. Ferrari et al., "Survival in highgrade osteosarcoma: improvement over 21 years at a single institution," Annals of Oncology, vol. 21, no. 6, pp. 1366-1373, 2009.

[36] A. Longhi, C. Errani, D. Gonzales-Arabio, C. Ferrari, and M. Mercuri, "Osteosarcoma in patients older than 65 years," Journal of Clinical Oncology, vol. 26, no. 33, pp. 5368-5373, 2008.

[37] M. T. Harting, K. P. Lally, R. J. Andrassy et al., "Age as a prognostic factor for patients with osteosarcoma: an analysis of 438 patients," Journal of Cancer Research and Clinical Oncology, vol. 136, no. 4, pp. 561-570, 2010.

[38] K. Okada, T. Hasegawa, J. Nishida et al., "Osteosarcomas after the age of 50: a clinicopathologic study of 64 cases-an experience in northern Japan," Annals of Surgical Oncology, vol. 11, no. 11, pp. 998-1004, 2004.

[39] B. Carsi and M. G. Rock, "Primary osteosarcoma in adults older than 40 years," Clinical Orthopaedics and Related Research, no. 397, pp. 53-61, 2002.

[40] B. Novakovic, "U.S. childhood cancer survival, 1973-1987," Medical and Pediatric Oncology, vol. 23, no. 6, pp. 480-486, 1994.

[41] G. Gatta, R. Capocaccia, C. Stiller et al., "Childhood cancer survival trends in Europe: a EUROCARE working group study," Journal of Clinical Oncology, vol. 23, no. 16, pp. 37423751, 2005.

[42] V. Arndt, B. Lacour, E. Steliarova-Foucher et al., "Up-todate monitoring of childhood cancer long-term survival in Europe: tumours of the sympathetic nervous system, retinoblastoma, renal and bone tumours, and soft tissue sarcomas," Annals of Oncology, vol. 18, no. 10, pp. 1722-1733, 2007.

[43] W. F. Taylor, J. C. Ivins, and D. J. Pritchard, "Trends and variability in survival among patients with osteosarcoma: a 7-year update," Mayo Clinic Proceedings, vol. 60, no. 2, pp. 91-104, 1985.

[44] R. Eyre, R. G. Feltbower, E. Mubwandarikwa, T. O. B. Eden, and R. J. Q. McNally, "Epidemiology of bone tumours in children and young adults," Pediatric Blood and Cancer, vol. 53, no. 6, pp. 941-952, 2009.

[45] E. Gazzano, L. Bergandi, C. Riganti et al., "Fluoride effects: the two faces of janus," Current Medicinal Chemistry, vol. 17, no. 22, pp. 2431-2441, 2010.

[46] E. B. Bassin, D. Wypij, R. B. Davis, and M. A. Mittleman, "Age-specific fluoride exposure in drinking water and osteosarcoma (United States)," Cancer Causes and Control, vol. 17, no. 4, pp. 421-428, 2006.
[47] C. W. Douglass and K. Joshipura, "Caution needed in fluoride and osteosarcoma study," Cancer Causes and Control, vol. 17, no. 4, pp. 481-482, 2006.

[48] E. Ron, "Cancer risks from medical radiation," Health Physics, vol. 85, no. 1, pp. 47-59, 2003.

[49] G. M. Dores, C. Metayer, R. E. Curtis et al., "Second malignant neoplasms among long-term survivors of Hodgkin's disease: a population-based evaluation over 25 years," Journal of Clinical Oncology, vol. 20, no. 16, pp. 3484-3494, 2002.

[50] M. S. Linet, K. P. Kim, and P. Rajaraman, "Children's exposure to diagnostic medical radiation and cancer risk: epidemiologic and dosimetric considerations," Pediatric Radiology, vol. 39, no. 1, pp. S4-S26, 2009.

[51] G. A. B. Lima, E. M. S. Gomes, R. C. Nunes et al., "Osteosarcoma and acromegaly: a case report and review of the literature," Journal of Endocrinological Investigation, vol. 29, no. 11, pp. 1006-1011, 2006.

[52] R. Troisi, M. N. Masters, K. Joshipura et al., "Perinatal factors, growth and development, and osteosarcoma risk," British Journal of Cancer, vol. 95, no. 11, pp. 1603-1607, 2006.

[53] A. Longhi, A. Pasini, A. Cicognani et al., "Height as a risk factor for osteosarcoma," Journal of Pediatric Hematology/Oncology, vol. 27, no. 6, pp. 314-318, 2005.

[54] P. E. Scranton Jr., F. A. DeCicco, R. S. Totten, and E. J. Yunis, "Prognostic factors in osteosarcoma. A review of 20 year's experience at the University of Pittsburgh Hlth Center Hospitals," Cancer, vol. 36, no. 6, pp. 2179-2191, 1975.

[55] M. Rytting, P. Pearson, A. K. Raymond et al., "Osteosarcoma in preadolescent patients," Clinical Orthopaedics and Related Research, no. 373, pp. 39-50, 2000.

[56] S. J. Withrow and C. Khanna, "Bridging the gap between experimental animals and humans in osteosarcoma," Cancer Treatment and Research, vol. 152, pp. 439-446, 2009.

[57] M. Pollak, "Insulin and insulin-like growth factor signalling in neoplasia," Nature Reviews Cancer, vol. 8, no. 12, pp. 915928, 2008.

[58] I. Cheng, D. O. Stram, K. L. Penney et al., "Common genetic variation in IGF1 and prostate cancer risk in the multiethnic cohort," Journal of the National Cancer Institute, vol. 98, no. 2, pp. 123-134, 2006.

[59] C. C. Kappel, M. C. Velez-Yanguas, S. Hirschfeld, and L. J. Helman, "Human osteosarcoma cell lines are dependent on insulin-like growth factor I for in vitro growth," Cancer Research, vol. 54, no. 10, pp. 2803-2807, 1994.

[60] M. N. Pollak, C. Polychronakos, and M. Richard, "Insulinlike growth factor I: a potent mitogen for human osteogenic sarcoma," Journal of the National Cancer Institute, vol. 82, no. 4, pp. 301-305, 1990.

[61] G. Fürstenberger and H. J. Senn, "Insulin-like growth factors and cancer," Lancet Oncology, vol. 3, no. 5, pp. 298-302, 2002.

[62] S. A. Savage, K. Woodson, E. Walk et al., "Analysis of genes critical for growth regulation identifies insulin-like growth factor 2 receptor variations with possible functional significance as risk factors for osteosarcoma," Cancer Epidemiology Biomarkers and Prevention, vol. 16, no. 8, pp. 1667-1674, 2007.

[63] J. F. Fraumeni Jr., "Stature and malignant tumors of bone in childhood and adolescence," Cancer, vol. 20, no. 6, pp. 967973, 1967.

[64] M. A. Goodman, J. H. McMaster, and A. L. Drash, "Metabolic and endocrine alterations in osteosarcoma patients," Cancer, vol. 42, no. 2, pp. 603-610, 1978.

[65] K. H. Gelberg, E. F. Fitzgerald, S. A. Hwang, and R. Dubrow, "Growth and development and other risk factors 
for osteosarcoma in children and young adults," International Journal of Epidemiology, vol. 26, no. 2, pp. 272-278, 1997.

[66] E. Ruza, E. Sotillo, L. Sierrasesúmaga, C. Azcona, and A. Patiño-García, "Analysis of polymorphisms of the vitamin $\mathrm{D}$ receptor, estrogen receptor, and collagen $\mathrm{I} \alpha 1$ genes and their relationship with height in children with bone cancer," Journal of Pediatric Hematology/Oncology, vol. 25, no. 10, pp. 780-786, 2003.

[67] S. J. Cotterill, C. M. Wright, M. S. Pearce, and A. W. Craft, "Stature of young people with malignant bone tumors," Pediatric Blood and Cancer, vol. 42, no. 1, pp. 59-63, 2004.

[68] L. A. Brostrom, U. Adamson, R. Filipsson, and K. Hall, "Longitudinal growth and dental development in osteosarcoma patients," Acta Orthopaedica Scandinavica, vol. 51, no. 5, pp. 755-759, 1980.

[69] W. P. Cool, R. J. Grimer, S. R. Carter, R. M. Tillman, and A. M. Davies, "Longitudinal growth following treatment for osteosarcoma," Sarcoma, vol. 2, no. 2, pp. 115-119, 1998.

[70] D. B. Glasser, K. Duane, J. M. Lane, J. H. Healey, and B. Caparros-Sison, "The effect of chemotherapy on growth in the skeletally immature individual," Clinical Orthopaedics and Related Research, no. 262, pp. 93-100, 1991.

[71] R. Vassilopoulou-Sellin, C. J. Walis, and N. A. Samaan, "Hormonal evaluation in patients with osteosarcoma," Journal of Surgical Oncology, vol. 28, no. 3, pp. 209-213, 1985.

[72] E. A. Operskalski, S. Preston-Martin, B. E. Henderson, and B. R. Visscher, "A case-control study of osteosarcoma in young persons," American Journal of Epidemiology, vol. 126, no. 1, pp. 118-126, 1987.

[73] C. H. Pui, R. K. Dodge, S. L. George, and A. A. Green, "Height at diagnosis of malignancies," Archives of Disease in Childhood, vol. 62, no. 5, pp. 495-499, 1987.

[74] J. D. Buckley, T. W. Pendergrass, C. M. Buckley et al., "Epidemiology of osteosarcoma and Ewing's sarcoma in childhood: a study of 305 cases by the children's cancer group," Cancer, vol. 83, no. 7, pp. 1440-1448, 1998.

[75] K. Silventoinen, S. Sammalisto, M. Perola et al., "Heritability of adult body height: a comparative study of twin cohorts in eight countries," Twin Research, vol. 6, no. 5, pp. 399-408, 2003.

[76] R. Randhawa and P. Cohen, "The role of the insulin-like growth factor system in prenatal growth," Molecular Genetics and Metabolism, vol. 86, no. 1-2, pp. 84-90, 2005.

[77] J. A. Ross, J. P. Perentesis, L. L. Robison, and S. M. Davies, "Big babies and infant leukemia: a role for insulin-like growth factor-1?" Cancer Causes and Control, vol. 7, no. 5, pp. 553$559,1996$.

[78] L. L. Hjalgrim, T. Westergaard, K. Rostgaard et al., "Birth weight as a risk factor for childhood leukemia: a metaanalysis of 18 epidemiologic studies," American Journal of Epidemiology, vol. 158, no. 8, pp. 724-735, 2003.

[79] J. Schüz and M. R. Forman, "Birthweight by gestational age and childhood cancer," Cancer Causes and Control, vol. 18, no. 6, pp. 655-663, 2007.

[80] T. Harder, A. Plagemann, and A. Harder, "Birth weight and subsequent risk of childhood primary brain tumors: a metaanalysis," American Journal of Epidemiology, vol. 168, no. 4, pp. 366-373, 2008.

[81] S. Ognjanovic, S. E. Carozza, E. J. Chow et al., "Birth characteristics and the risk of childhood rhabdomyosarcoma based on histological subtype," British Journal of Cancer, vol. 102, no. 1, pp. 227-231, 2010.

[82] J. Schuz, L. S. Schmidt, P. Kogner et al., "Birth characteristics and Wilmstumours in children in the Nordic countries: a register-based case-control study," International Journal of Cancer, 2010. In press.

[83] W. M. Leisenring, N. E. Breslow, I. E. Evans, J. B. Beckwith, M. J. Coppes, and P. Grundy, "Increased birth weights of National Wilms' Tumor Study patients suggest a growth factor excess," Cancer Research, vol. 54, no. 17, pp. 46804683, 1994.

[84] A. Smith, T. Lightfoot, J. Simpson, and E. Roman, "Birth weight, sex and childhood cancer: a report from the United Kingdom Childhood Cancer Study," Cancer Epidemiology, vol. 33, no. 5, pp. 363-367, 2009.

[85] K. B. Michels and F. Xue, "Role of birthweight in the etiology of breast cancer," International Journal of Cancer, vol. 119, no. 9, pp. 2007-2025, 2006.

[86] M. Eriksson, H. Wedel, M. A. Wallander et al., "The impact of birth weight on prostate cancer incidence and mortality in a population-based study of men born in 1913 and followed up from 50 to 85 years of age," Prostate, vol. 67, no. 11, pp. 1247-1254, 2007.

[87] A. L. Hartley, J. M. Birch, P. A. McKinney et al., "The Inter-Regional Epidemiological Study of Childhood Cancer (IRESCC): case control study of children with bone and soft tissue sarcomas," British Journal of Cancer, vol. 58, no. 6, pp. 838-842, 1988.

[88] A. Goode and R. Layfield, "Recent advances in understanding the molecular basis of Paget disease of bone," Journal of Clinical Pathology, vol. 63, no. 3, pp. 199-203, 2010.

[89] T. Cundy and M. Bolland, "Paget disease of bone," Trends in Endocrinology and Metabolism, vol. 19, no. 7, pp. 246-253, 2008.

[90] M. F. Hansen, M. Seton, and A. Merchant, "Osteosarcoma in Paget's disease of bone," Journal of Bone and Mineral Research, vol. 21, pp. P58-P63, 2006.

[91] B. Fuchs and D. J. Pritchard, "Etiology of osteosarcoma," Clinical Orthopaedics and Related Research, no. 397, pp. 40$52,2002$.

[92] N. Laurin, J. P. Brown, J. Morissette, and V. Raymond, "Recurrent mutation of the gene encoding sequestosome 1 (SQSTM1/p62) in paget disease of bone," American Journal of Human Genetics, vol. 70, no. 6, pp. 1582-1588, 2002.

[93] K. Al-Romaih, J. Bayani, J. Vorobyova et al., "Chromosomal instability in osteosarcoma and its association with centrosome abnormalities," Cancer Genetics and Cytogenetics, vol. 144, no. 2, pp. 91-99, 2003.

[94] A. A. Sandberg and J. A. Bridge, "Updates on the cytogenetics and molecular genetics of bone and soft tissue tumors: osteosarcoma and related tumors," Cancer Genetics and Cytogenetics, vol. 145, no. 1, pp. 1-30, 2003.

[95] A. Patino-Garcia, E. Sotillo-Pineiro, C. Modesto, and L. Sierrasesumaga, "Analysis of the human tumour necrosis factoralpha $(\mathrm{TNF} \alpha)$ gene promoter polymorphisms in children with bone cancer," Journal of Medical Genetics, vol. 37, no. 10, pp. 789-792, 2000.

[96] S. A. Savage, L. Burdett, R. Troisi, C. Douglass, R. N. Hoover, and S. J. Chanock, "Germ-line genetic variation of TP53 in osteosarcoma," Pediatric Blood and Cancer, vol. 49, no. 1, pp. 28-33, 2007.

[97] N. V. Koshkina, E. S. Kleinerman, G. Li, C. C. Zhao, Q. Wei, and E. M. Sturgis, "Exploratory analysis of Fas gene polymorphisms in pediatric osteosarcoma patients," Journal of Pediatric Hematology/Oncology, vol. 29, no. 12, pp. 815821, 2007.

[98] G. Toffoli, P. Biason, A. Russo et al., "Effect of TP53 Arg72Pro and MDM2 SNP309 polymorphisms on the risk of 
high-grade osteosarcoma development and survival," Clinical Cancer Research, vol. 15, no. 10, pp. 3550-3556, 2009.

[99] Y.-S. Hu, Y. Pan, W.-H. Li, Y. Zhang, J. Li, and B.-A. $\mathrm{Ma}$, "Association between TGFBR1 $* 6 \mathrm{~A}$ and osteosarcoma: a Chinese case-control study," BMC Cancer, vol. 10, article 169, 2010.

[100] L. Mirabello, S. I. Berndt, G. F. Seratti et al., "Genetic variation at chromosome 8q24 in osteosarcoma cases and controls," Carcinogenesis, vol. 31, no. 8, pp. 1400-1404, 2010.

[101] F. P. Li and J. F. Fraumeni Jr., "Soft-tissue sarcomas, breast cancer, and other neoplasms. A familial syndrome?" Annals of Internal Medicine, vol. 71, no. 4, pp. 747-752, 1969.

[102] K. Schneider and J. Garber, "Li-Fraumeni Syndrome," in Gene Reviews, R. A. Pagon, T. C. Bird, C. R. Dolan, and K. Stephens, Eds., University of Washington, Seattle, Wash, USA, 1993.

[103] D. Malkin, F. P. Li, L. C. Strong et al., "Germ line p53 mutations in a familial syndrome of breast cancer, sarcomas, and other neoplasms," Science, vol. 250, no. 4985, pp. 1233$1238,1990$.

[104] M. Olivier, M. Hollstein, and P. Hainaut, "TP53 mutations in human cancers: origins, consequences, and clinical use," Cold Spring Harbor Perspectives in Biology, vol. 2, no. 1, article a001008, 2010.

[105] J. S. Wunder, N. Gokgoz, R. Parkes et al., "TP53 mutations and outcome in osteosarcoma: a prospective, multicenter study," Journal of Clinical Oncology, vol. 23, no. 7, pp. 14831490, 2005.

[106] D. Lohmann, "Retinoblastoma," Advances in Experimental Medicine and Biology, vol. 685, pp. 220-227, 2010.

[107] R. A. Kleinerman, M. A. Tucker, D. H. Abramson, J. M. Seddon, R. E. Tarone, and J. F. Fraumeni Jr., "Risk of soft tissue sarcomas by individual subtype in survivors of hereditary retinoblastoma," Journal of the National Cancer Institute, vol. 99, no. 1, pp. 24-31, 2007.

[108] C. L. Yu, M. A. Tucker, D. H. Abramson et al., "Cause-specific mortality in long-term survivors of retinoblastoma," Journal of the National Cancer Institute, vol. 101, no. 8, pp. 581-591, 2009.

[109] L. Larizza, G. Roversi, and L. Volpi, "Rothmund-thomson syndrome," Orphanet Journal of Rare Diseases, vol. 5, no. 1, article 2, 2010.

[110] L. L. Wang and S. E. Plon, "Rothmund-Thomson syndrome," in Gene Reviews, R. A. Pagon, T. C. Bird, C. R. Dolan, and K. Stephens, Eds., University of Washington, Seattle, Wash, USA, 1993.

[111] L. L. Wang, M. L. Levy, R. A. Lewis et al., "Clinical manifestations in a cohort of 41 Rothmund-Thomson syndrome patients," American Journal of Medical Genetics, vol. 102, no. 1, pp. 11-17, 2001.

[112] M. M. Sanz and J. German, "Bloom's syndrome," in Gene Reviews, R. A. Pagon, T. C. Bird, C. R. Dolan, and K. Stephens, Eds., University of Washington, Seattle, Wash, USA, 1993.

[113] D. F. Leistritz, N. Hanson, G. M. Martin, and J. Oshima, "Werner syndrome," in Gene Reviews, R. A. Pagon, T. C. Bird, C. R. Dolan, and K. Stephens, Eds., University of Washington, Seattle, Wash, USA, 1993.

[114] M. Muftuoglu, J. Oshima, C. Kobbe, W.-H. Cheng, D. F. Leistritz, and V. A. Bohr, "The clinical characteristics of Werner syndrome: molecular and biochemical diagnosis," Human Genetics, vol. 124, no. 4, pp. 369-377, 2008.

[115] M. Goto, R. W. Miller, Y. Ishikawa, and H. Sugano, "Excess of rare cancers in Werner syndrome (adult progeria)," Cancer
Epidemiology, Biomarkers and Prevention, vol. 5, pp. 239-246, 1996.

[116] Y. Ishikawa, R. W. Miller, R. Machinami, H. Sugano, and M. Goto, "Atypical osteosarcomas in Werner Syndrome (Adult Progeria)," Japanese Journal of Cancer Research, vol. 91, no. 12, pp. 1345-1349, 2000.

[117] C. Clinton and H. T. Gazda, "Diamond-Blackfan anemia," in Gene Reviews, R. A. Pagon, T. C. Bird, C. R. Dolan, and K. Stephens, Eds., University of Washington, Seattle, Wash, USA, 1993.

[118] J. M. Lipton, N. Federman, Y. Khabbaze et al., "Osteogenic sarcoma associated with Diamond-Blackfan anemia: a report from the Diamond-Blackfan anemia registry," Journal of Pediatric Hematology/Oncology, vol. 23, no. 1, pp. 39-44, 2001.

[119] G. L. Bond, W. Hu, E. E. Bond et al., "A single nucleotide polymorphism in the MDM2 promoter attenuates the p53 tumor suppressor pathway and accelerates tumor formation in humans," Cell, vol. 119, no. 5, pp. 591-602, 2004.

[120] A. Patino-Garcia, E. Sotillo-Pineiro, C. Modesto, and L. Sierrasesumaga, "Analysis of the human tumour necrosis factoralpha $(\mathrm{TNF} \alpha)$ gene promoter polymorphisms in children with bone cancer," Journal of Medical Genetics, vol. 37, no. 10, pp. 789-791, 2000.

[121] C. Whibley, P. D. P. Pharoah, and M. Hollstein, "p53 polymorphisms: cancer implications," Nature Reviews Cancer, vol. 9, no. 2, pp. 95-107, 2009.

[122] G. Bougeard, S. Baert-Desurmont, I. Tournier et al., "Impact of the MDM2 SNP309 and p53 Arg72Pro polymorphism on age of tumour onset in Li-Fraumeni syndrome," Journal of Medical Genetics, vol. 43, no. 6, pp. 531-533, 2006.

[123] S. I. Berndt, J. D. Potter, A. Hazra et al., "Pooled analysis of genetic variation at chromosome 8q24 and colorectal neoplasia risk," Human Molecular Genetics, vol. 17, no. 17, pp. 2665-2672, 2008.

[124] O. Fletcher, N. Johnson, L. Gibson et al., "Association of genetic variants at $8 \mathrm{q} 24$ with breast cancer risk," Cancer Epidemiology Biomarkers and Prevention, vol. 17, no. 3, pp. 702-705, 2008.

[125] C. A. Haiman, N. Patterson, M. L. Freedman et al., "Multiple regions within 8q24 independently affect risk for prostate cancer," Nature Genetics, vol. 39, no. 5, pp. 638-644, 2007.

[126] M. M. Pomerantz, N. Ahmadiyeh, LI. Jia et al., "The 8q24 cancer risk variant rs6983267 shows long-range interaction with MYC in colorectal cancer," Nature Genetics, vol. 41, no. 8, pp. 882-884, 2009.

[127] M. Jain, C. Arvanitis, K. Chu et al., "Sustained loss of a neoplastic phenotype by brief inactivation of MYC," Science, vol. 297, no. 5578, pp. 102-104, 2002.

[128] Z. Zhang, H. Xue, W. Gong et al., "FAS promoter polymorphisms and cancer risk: a meta-analysis based on 34 casecontrol studies," Carcinogenesis, vol. 30, no. 3, pp. 487-493, 2009.

[129] J. Zhu, C. Qin, M. Wang et al., "Functional polymorphisms in cell death pathway genes and risk of renal cell carcinoma," Molecular Carcinogenesis, vol. 49, no. 9, pp. 810-817, 2010.

[130] R. Y. Liao, C. Mao, L. X. Qiu, H. Ding, Q. Chen, and H. F. Pan, "TGFBR $1 * 6 \mathrm{~A} / 9 \mathrm{~A}$ polymorphism and cancer risk: a meta-analysis of 13,662 cases and 14,147 controls," Molecular Biology Reports, vol. 37, pp. 3227-3232, 2010.

[131] R. C. Brown, T. Dwyer, C. Kasten et al., "Cohort profile: the international childhood cancer cohort consortium (I4C)," International Journal of Epidemiology, vol. 36, no. 4, pp. 724730, 2007. 


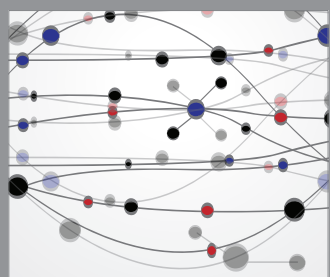

The Scientific World Journal
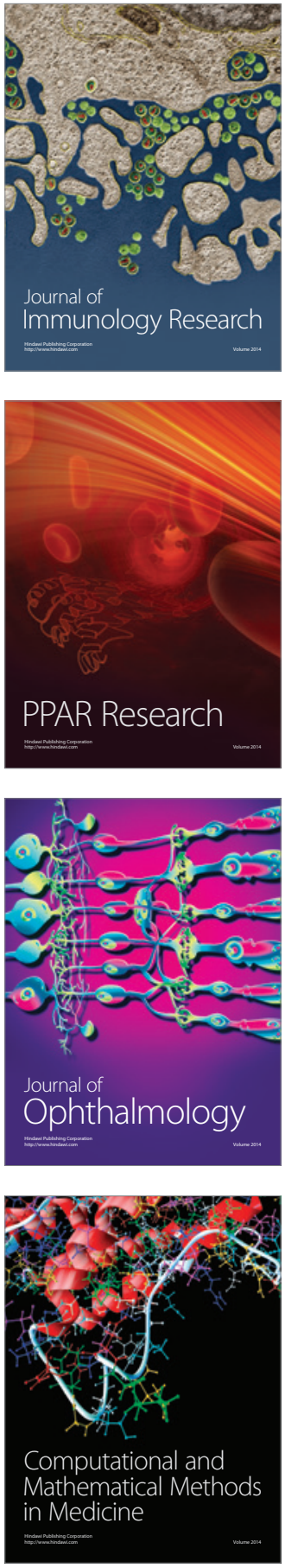

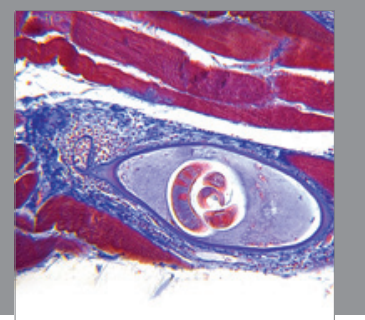

Gastroenterology

Research and Practice
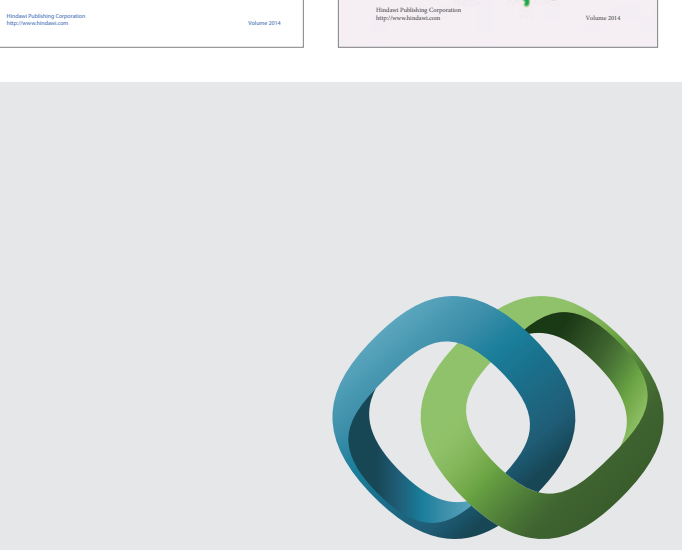

\section{Hindawi}

Submit your manuscripts at

http://www.hindawi.com
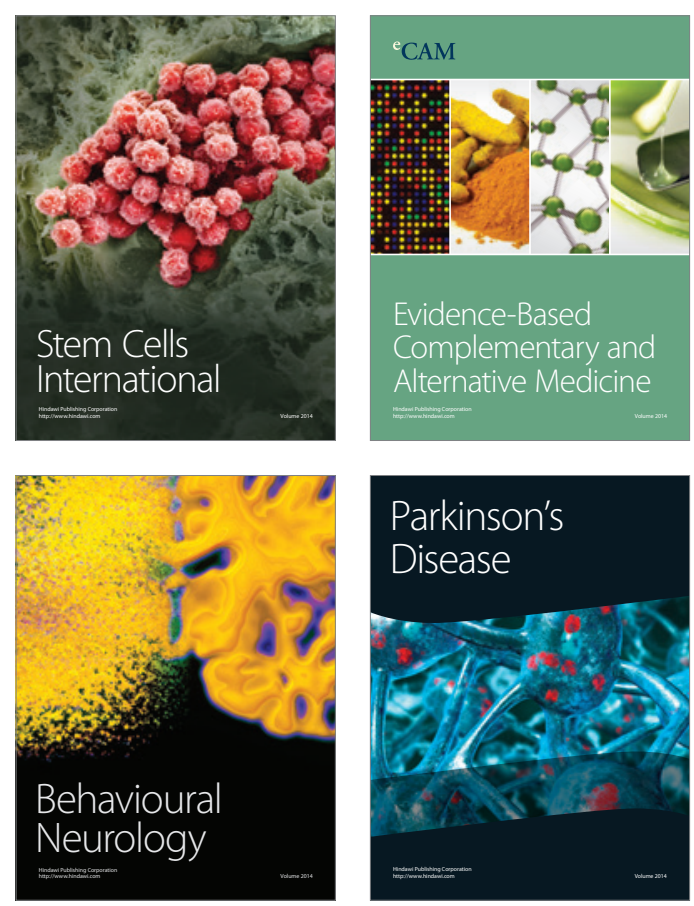

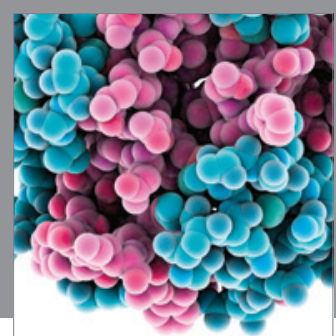

Journal of
Diabetes Research

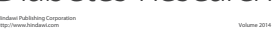

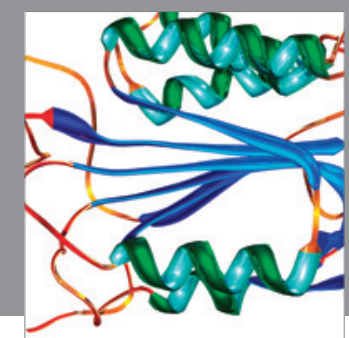

Disease Markers
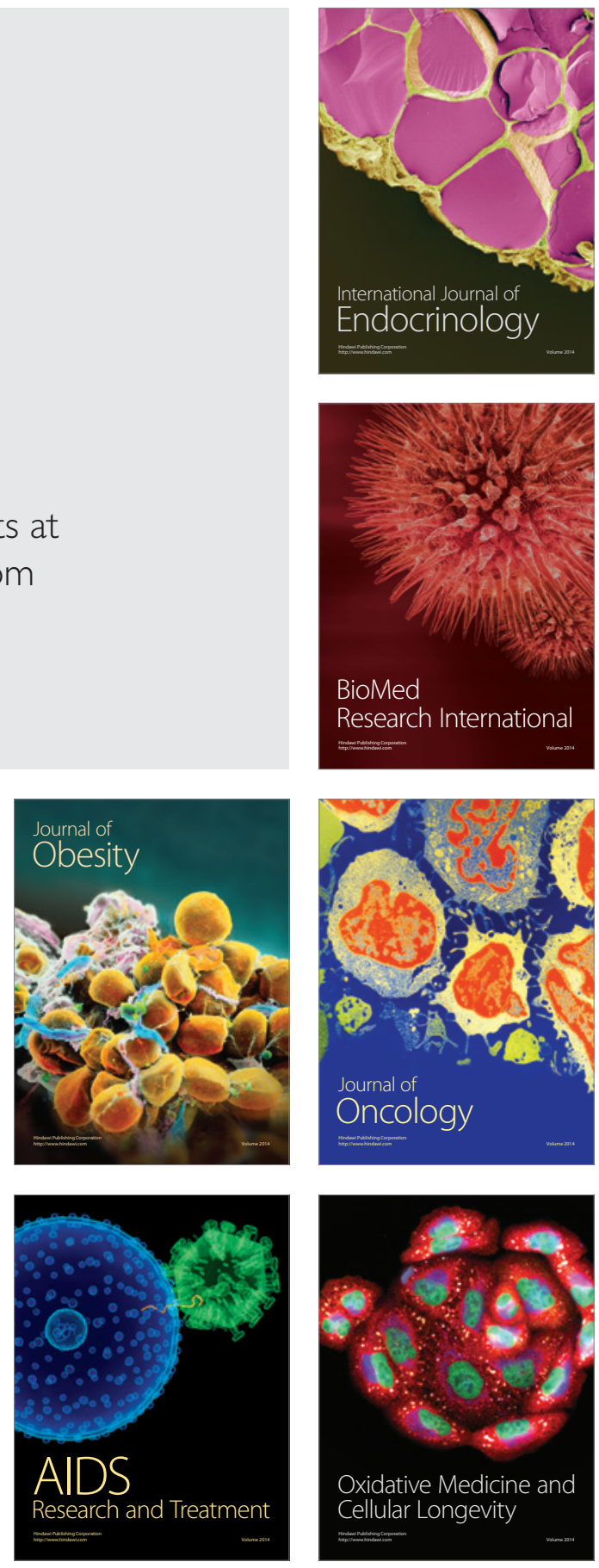